\title{
Diaphragm thickening fraction predicts noninvasive ventilation outcome: a preliminary physiological study
}

\author{
Giovanna Mercurio ${ }^{1 *} \mathbb{D}$, Sonia D’Arrigo ${ }^{1}$, Rossana Moroni², Domenico Luca Grieco', Luca Salvatore Menga', \\ Anna Romano ${ }^{3}$, Maria Giuseppina Annetta ${ }^{1}$, Maria Grazia Bocci ${ }^{1}$, Davide Eleuteri ${ }^{1}$, Giuseppe Bello' \\ Luca Montini ${ }^{1,3}$, Mariano Alberto Pennisi ${ }^{1,3}$, Giorgio Conti ${ }^{1,3}$ and Massimo Antonelli ${ }^{1,3}$
}

\begin{abstract}
Background: A correlation between unsuccessful noninvasive ventilation (NIV) and poor outcome has been suggested in de-novo Acute Respiratory Failure (ARF) patients. Consequently, it is of paramount importance to identify accurate predictors of NIV outcome. The aim of our preliminary study is to evaluate the Diaphragmatic Thickening Fraction (DTF) and the respiratory rate/DTF ratio as predictors of NIV outcome in de-novo ARF patients.
\end{abstract}

Methods: Over 36 months, we studied patients admitted to the emergency department with a diagnosis of de-novo ARF and requiring NIV treatment. DTF and respiratory rate/DTF ratio were measured by 2 trained operators at baseline, at 1,4,12, 24, 48, 72 and 96 h of NIV treatment and/or until NIV discontinuation or intubation. Receiver operating characteristic (ROC) curve analysis was performed to evaluate the ability of DTF and respiratory rate/DTF ratio to distinguish between patients who were successfully weaned and those who failed.

Results: Eighteen patients were included. We found overall good repeatability of DTF assessment, with Intra-class Correlation Coefficient (ICC) of 0.82 (95\% confidence interval 0.72-0.88). The cut-off values of DTF for prediction of NIV failure were $<36.3 \%$ and $<37.1 \%$ for the operator 1 and $2(p<0.0001)$, respectively. The cut-off value of respiratory rate/DTF ratio for prediction of NIV failure was $>0.6$ for both operators $(p<0.0001)$.

Conclusion: DTF and respiratory rate/DTF ratio may both represent valid, feasible and noninvasive tools to predict NIV outcome in patients with de-novo ARF.

Trial registration ClinicalTrials.gov Identifier: NCT02976233, registered 26 November 2016.

Keywords: Acute respiratory failure, Noninvasive ventilation, Ultrasound, Diaphragm thickening fraction, Rapid shallow breathing index

*Correspondence: giovanna.mercurio@policlinicogemelli.it

${ }^{1}$ Department of Anesthesiology, Intensive Care and Emergency

Medicine, Fondazione Policlinico Universitario A. Gemelli IRCCS, Largo A. Gemelli, 8, 00168 Rome, Italy

Full list of author information is available at the end of the article

\section{Background}

Over the last 2 decades, it has been suggested that noninvasive ventilation (NIV) might be effective in avoiding intubation $[1,2]$ and improving survival in the acute care setting [3] when compared to conventional oxygen therapy [4].

Nonetheless, its use in de-novo Acute Respiratory Failure (ARF) is debated, since a strict association between the unsuccessful NIV and the poor outcome has been original author(s) and the source, provide a link to the Creative Commons licence, and indicate if changes were made. The images or other third party material in this article are included in the article's Creative Commons licence, unless indicated otherwise in a credit line to the material. If material is not included in the article's Creative Commons licence and your intended use is not permitted by statutory regulation or exceeds the permitted use, you will need to obtain permission directly from the copyright holder. To view a copy of this licence, visit http://creativecommons.org/licenses/by/4.0/. The Creative Commons Public Domain Dedication waiver (http://creativeco mmons.org/publicdomain/zero/1.0/) applies to the data made available in this article, unless otherwise stated in a credit line to the data. 
suggested [5]. Given the risks associated with either premature or delayed NIV discontinuation [6], evaluating weaning readiness, as well as correct timing of intubation, is a critical challenge in patients with de-novo ARF.

Up to now, there are few available bedside measurements for prediction of NIV outcome and the decision to discontinue NIV is mainly based on clinical and physiologic parameters $[7,8]$.

Indeed, although sophisticated methods have been proposed to predict weaning outcome [8], none of these methods has ever achieved a wide bedside use because of their invasiveness, of the inconsistent results, and of the need for trainee personnel and complicated equipment. Consequently, the rapid shallow breathing index is still preferable to these methods because of its simpler application and more immediate interpretation [9].

The diaphragm is the main respiratory muscle, and its dysfunction has been associated with prolonged mechanical ventilation and weaning failure $[10,11]$.

Recently, ultrasound has been used at the bedside in acutely ill patients both for rapid functional assessment of the skeletal muscles [12] and for evaluation of diaphragmatic function [13] with minimal invasiveness and without any X-ray exposure. Ultrasound can be used to measure the excursions of the diaphragm, its thickness and its speed of contraction $[14,15]$, yielding information about the muscle function and the respiratory efficiency.

Indeed, diaphragmatic thickness (DT) correlates with the strength and the shortening of the muscle $[16,17]$. The volume of muscle mass remains constant during diaphragm contraction. Consequently, as the muscle shortens it becomes thicker, so that DT changes are inversely related to changes in the length of the muscle. Moreover, the magnitude of diaphragm shortening and contraction may predict successful extubation in invasively ventilated patients [18].

Recently, Vivier et al. [15] have conducted a physiological study to assess the accuracy of Diaphragm Thickening Fraction (DTF) and its contribution to the respiratory workload in 12 critically ill patients requiring planned NIV after extubation. The patients were studied either while spontaneously breathing or during NIV at three different levels of pressure support, measuring DTF and diaphragmatic Pressure-Time Product per breath $\left(\mathrm{PTP}_{\mathrm{di}}\right)$.

These authors found that increases in the level of Pressure Support were associated with a reduction in both $\mathrm{PTP}_{\mathrm{di}}$ and DTF, and that there was a significant correlation between $\operatorname{PTP}_{\mathrm{di}}$ and DTF $(\rho=0.74, p<0.001)$. They concluded that DTF is a noninvasive method that may be useful in evaluating the diaphragm contribution to the respiratory workload in acutely ill patients undergoing NIV treatment.
The aim of this preliminary study is to assess whether measurements of DTF and its relationship with respiratory rate may predict NIV outcome in patients with denovo ARF admitted to the emergency department.

\section{Methods}

All patients with de-novo ARF requiring NIV treatment admitted to the emergency department at Fondazione Policlinico Universitario A. Gemelli, IRCCS Rome-Italy were included into this preliminary study.

The protocol was approved by the local Ethics Committee (Prot 20813/16 ID 1200) and informed consent was obtained by all study participants.

The criteria for eligibility were de-novo ARF in the presence of respiratory rate $\geq 35$ breaths per minute, a ratio of the $\mathrm{PaO}_{2}$ to the fraction of inspired oxygen $\left(\mathrm{PaO}_{2} / \mathrm{FiO}_{2}\right)$ of less than 200 with oxygen therapy through a Venturi mask or a High Flow Nasal Cannula (50 L/min) and active contraction of the accessory muscles of respiration or paradoxical abdominal motion.

The exclusion criteria were: age $<18$ years, pregnancy, diaphragm paralysis, exacerbation of asthma and/or chronic obstructive pulmonary disease, neuromuscular disorders, severe obesity with Body Mass Index $(\mathrm{BMI}) \geq 35 \mathrm{~kg} / \mathrm{m}^{2}$, palliative NIV in patients with malignancy, ineffective cough and/or inability to protect airways.

Noninvasive Pressure Support Ventilation (PSV) with positive end-expiratory pressure (PEEP) was delivered through either a facial mask with an inflatable soft cushion seal (Gibeck, Upplands, Sweden; Vitalsigns, Towota, NJ, USA) or with a clear, latex-free helmet (CaStar, Starmed, Mirandola, Italy), according to a clinical decision.

In the patients with a facial mask, PSV was started at $10 \mathrm{cmH}_{2} \mathrm{O}$ and increased with progressive stepwise increments of $2-3 \mathrm{cmH}_{2} \mathrm{O}$, to obtain an exhaled tidal volume of $6 \mathrm{~mL} / \mathrm{kg}$, respiratory rate $\leq 25$ breaths per minute, patient comfort and disappearance of accessory muscle activity or paradoxical abdominal motion. PEEP was increased with stepwise increments of $2-3 \mathrm{cmH}_{2} \mathrm{O}$ up to $12 \mathrm{cmH}_{2} \mathrm{O}$ to ensure peripheral oxygen saturation $\left(\mathrm{SpO}_{2}\right)$ of $\geq 90 \%$ with the lowest possible $\mathrm{FiO}_{2}$.

In the patients with a helmet, a soft cushion around the neck provides sealing of the interface, reducing air leaks and allowing high levels of PEEP. PEEP was set to $10-12 \mathrm{cmH}_{2} \mathrm{O}$ to ensure adequate inflation of the interface, and since part of the volume delivered to the system was used to distend the helmet without reaching the patient PS levels were increased with stepwise increments of $2-3 \mathrm{cmH}_{2} \mathrm{O}$ up to $15-18 \mathrm{cmH}_{2} \mathrm{O}$. Ventilator settings were then adjusted according to $\mathrm{SpO}_{2}$ and measurements of arterial blood gases. The flow trigger was set 
at $3 \mathrm{~L} / \mathrm{min}$, checking out for the absence of auto-triggering phenomena.

\section{Criteria for immediate intubation}

Criteria for immediate intubation included the inability to maintain a $\mathrm{PaO}_{2} / \mathrm{FiO}_{2}>140$, the onset of seizures or coma (Glasgow coma score $\leq 8$ ), hemodynamic instability (systolic blood pressure $\leq 80 \mathrm{mmHg}$ despite adequate fluid resuscitation and/or increased needs of vasopressors [norepinephrine $>0.5 \mathrm{mcg} / \mathrm{kg} / \mathrm{min}$ ] and $/$ or electrocardiographic signs of ischemia or arrhythmias), intolerance of the interface, ineffective cough, discomfort, or the need for an urgent surgery. After intubation, all patients were ventilated with a low-tidal-volume protective ventilatory strategy [19].

\section{Criteria for NIV weaning}

NIV support was progressively reduced in accordance with the degree of both gas exchange and clinical improvement and discontinued when the patient was able to maintain respiratory rate $\leq$ than 25 breaths per minute and $\mathrm{PaO}_{2}>75 \mathrm{mmHg}$ with a $\mathrm{FiO}_{2}$ of 0.5 without ventilatory support.

\section{Definitions and measurements}

On the emergency department admission, we recorded the patients' characteristics, including the Simplified Acute Physiologic Score (SAPS II) [20], the Richmond Agitation-Sedation Scale (RASS) [21], the diagnosis and the comorbidities.

Arterial blood gas levels, respiratory and hemodynamic parameters were measured at baseline, at 1, 4, 12, 24, 48, 72 and $96 \mathrm{~h}$ or until intubation.

Improvement in gas exchange was defined as the ability to increase $\mathrm{PaO}_{2} / \mathrm{FiO}_{2}$ above 200 or to increase this ratio $>100$ over the baseline.

Improvement in respiratory rate was defined as a respiratory rate $\leq 25$ breaths per minute or disappearance of accessory muscles' use and paradoxical abdominal motion.

NIV success was defined as the improvement in respiratory rate and gas exchange within the first $96 \mathrm{~h}$ of treatment.

The need of intubation and/or failure to reach an improvement in respiratory rate and gas exchange at any point of the study was defined NIV failure.

Patients were monitored for the development of sepsis, septic shock and Acute Respiratory Distress Syndrome (ARDS) [22, 23].

We also recorded the duration of mechanical ventilation, the emergency department and the hospital length of stay, as well as the emergency department and in-hospital mortality.

\section{Sonographic definitions and measurements}

All patients were placed in a semi-recumbent position with the right arm elevated. DT was assessed through a linear high-frequency $(7-10 \mathrm{MHz}$ ) probe (Vivid E, General Electrics). The right diaphragm was imaged by placing the probe perpendicular to the chest wall on the mid-axillary line at the apposition point of the diaphragm, between the 8th and the 10th intercostal spaces [15]. In this area, the diaphragm is visualized as a three layer structure with a non-echogenic central layer between two echogenic layers, the peritoneum and the diaphragmatic pleurae. The change in DT between endexpiration and end-inspiration (DTF) was expressed as $\left(\mathrm{DT}_{\text {end-inspiration }}-\mathrm{DT}_{\text {end-expiration }} / \mathrm{DT}_{\text {end-expiration }}\right) \times 100$ [15]. In each patient, DTF was estimated as the mean value measured in three to five breaths and the examinations were carried out in blind by 2 different and appropriately trained operators [24].

We calculated the ratio between respiratory rate and DTF (respiratory rate/DTF) at any time point.

Images were obtained at baseline, at 1, 4, 12, 24, 48, 72 and $96 \mathrm{~h}$ of NIV treatment and/or until NIV discontinuation or intubation.

\section{Objectives}

The primary objective of our study was to assess the feasibility of ultrasound measurement of DTF and its accuracy in predicting NIV outcome in patients with de-novo ARF.

We also aimed to evaluate the possibility of predicting the need of endotracheal intubation using DTF and its relationship with respiratory rate.

\section{Statistics}

Statistical analysis (MedCalc Software bvba, Ostend, Belgium; http://www.medcalc.org; 2014) was preliminarily performed on 18 patients. This sample size was esteemed to be appropriate, since it was enough to identify a disagreement rate between operators of $\pi_{\mathrm{D}}=5 \%$, with $\alpha=0.05$ and power $=80 \%$, with regards to the primary study objectives.

Continuous variables with normal distributions were expressed as means and standard deviation (SD) and assessed with the Student's t-test while those with non-normal distributions were expressed as medians and interquartile ranges [IQR] and assessed with the Mann-Whitney test. 
Repeated measures over time were evaluated with the analysis of variance (ANOVA).

Normality of data was verified with the KolmogorovSmirnov test. Categorical variables were presented as group proportions and analyzed with the Chi-square test or Fisher exact's test, as appropriate. A two-tailed $p$ value of less than 0.05 was considered statistically significant.

Receiver operating characteristic (ROC) curve analyses were performed to assess the ability of both DTF and respiratory rate/DTF ratio to distinguish between patients who succeeded weaning and those who failed it. The optimal criterion value (cut-off value) took into account sensitivity and specificity.

As regarding the ultrasound measurements, the reproducibility was expressed by the ICC [25].

\section{Results}

Over a period of 36 months, 53 eligible patients were screened for inclusion. Of these, 32 patients were excluded and 21 were enrolled. Three patients were excluded after inclusion for a concomitant diagnosis of chronic obstructive pulmonary disease unknown at the time of enrolment, so that only18 patients ( 8 males, 44.5\%) were included into the final analysis (Fig. 1).

Mean age (SD) was 66 (19) years, with a mean (SD) SAPS II score of 44 (4). On admission to the emergency department the median [IQR] $\mathrm{PaO}_{2} / \mathrm{FiO}_{2}$ ratio was 89.4 [77.4-117.5], the median $\mathrm{PaCO}_{2}$ was 30.6 [29.3-39.2] $\mathrm{mmHg}$, and the median respiratory rate was 38 [3644.2] breaths per minute. The cause of acute hypoxic respiratory failure on admission was pneumonia in more than $70 \%$ of included patients.

Demographic and clinical characteristics of the population are reported in Table 1.

\section{Sonographic measurements}

We found overall good repeatability of DTF assessment, with an ICC of 0.82 (95\% CI 0.72-0.88).

The cut-off value of DTF $<36.3 \%$ for the operator 1 significantly predicted NIV failure $(p<0.0001)$ with sensitivity of $71.7 \%$ (95\% CI $56.5-84.0$ ) and specificity of $94.3 \%$ (95\% CI 80.8-99.3) (Fig. 2A).

The cut off value of DTF $<37.1 \%$ for the operator 2 significantly predicted NIV failure $(p<0.0001)$ with sensitivity of $65.2 \%$ (95\% CI $49.8-78.6)$ and specificity of $91.4 \%$ (95\% CI 76.9-98.2) (Fig. 2B).

We also found that the cut-off value of respiratory rate/ DTF that distinguished between NIV failure and success was $>0.6$ for the operator $1(p<0.0001)$ with sensitivity of $78.3 \%$ (95\% CI 63.6-89.1) and specificity of $97.1 \%(95 \%$ CI 85.1-99.9) (Fig. 3A).

The cut-off value of respiratory rate/DTF that distinguished between NIV failure and success was also $>0.6$ for the operator $2(p<0.0001)$ with sensitivity of $73.9 \%$ (95\% CI 58.9-85.7) and specificity of $91.4 \%$ (95\% CI 76.9-98.2) (Fig. 3B).

NIV success patients compared to NIV failure patients had significantly higher mean (SD) DTF in the first $96 \mathrm{~h}$ [52 (23) \% vs 34 (19) \%, $p<0.001$ (Fig. 4A) and lower respiratory rate/DTF $[0.58(0.39)$ vs $1.24(0.63), p<0.001]$ (Fig. 4B).

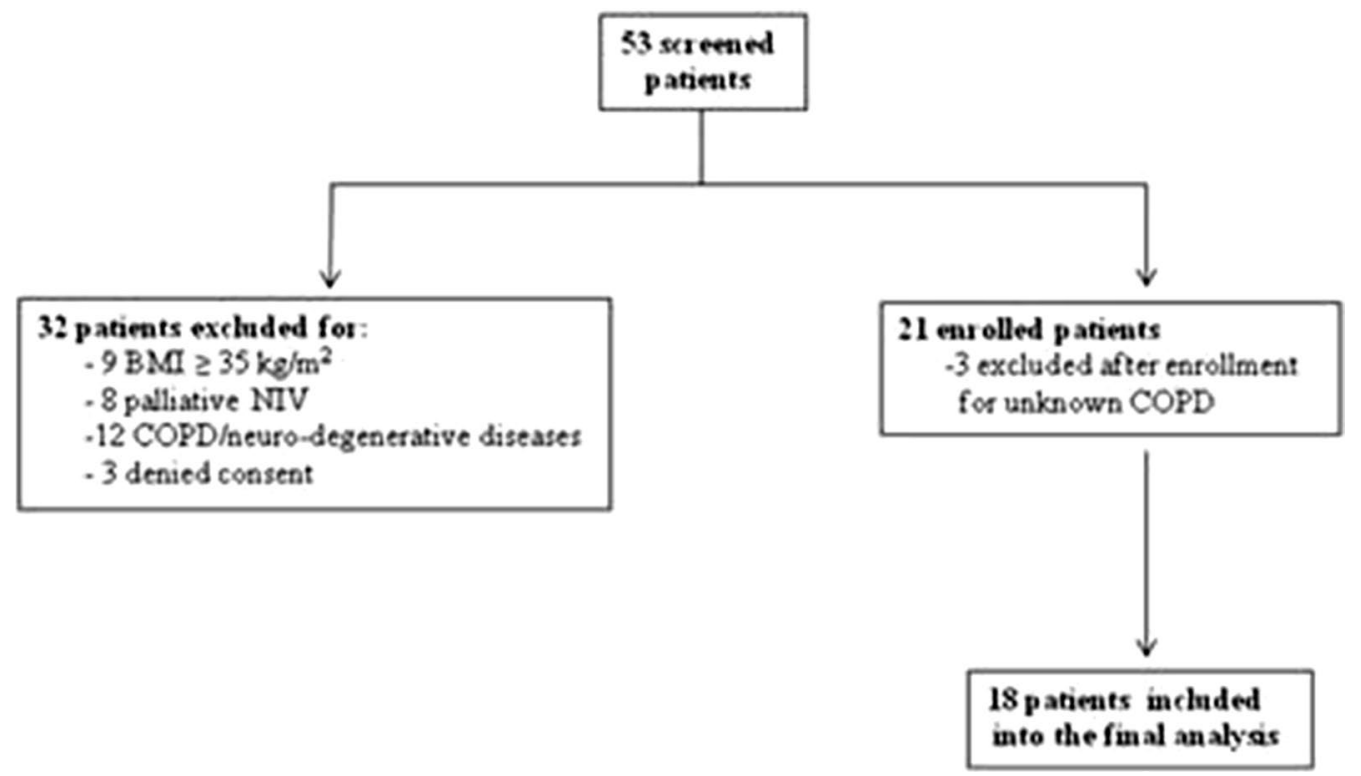

Fig. 1 Flow chart of screened and enrolled patients 
Table 1 Characteristics of patients at baseline, in the whole population

\begin{tabular}{|c|c|}
\hline Characteristics & All patients $(n=18)$ \\
\hline Age (years) & $66 \pm 19$ \\
\hline Male, $n(\%)$ & $8(44.5)$ \\
\hline äBI $\left(\mathrm{kg} / \mathrm{m}^{2}\right)$ & $25 \pm 4$ \\
\hline bSAPS II score & $44 \pm 4$ \\
\hline RASS score & $1[0-1]$ \\
\hline $\mathrm{PaO}_{2} / \mathrm{FiO}_{2}(\mathrm{mmHg})$ & $89.4[77.4-117.5]$ \\
\hline $\mathrm{PaCO}_{2}(\mathrm{mmHg})$ & $30.6[29.3-39.2]$ \\
\hline Respiratory rate, breaths per minute & $38[36-44.2]$ \\
\hline \multicolumn{2}{|c|}{$\begin{array}{l}\text { Acute hypoxemic respiratory failure causes on emergency department } \\
\text { admission }\end{array}$} \\
\hline Pneumoniae, $n(\%)$ & $13(72.2)$ \\
\hline Post-surgery, $n(\%)$ & $1(5.5)$ \\
\hline Abdominal abscess, $n(\%)$ & $1(5.5)$ \\
\hline Hepato-renal syndrome, $n$ (\%) & $1(5.5)$ \\
\hline Non cardiogenic pulmonary oedema, $n$ (\%) & $2(11.1)$ \\
\hline \multicolumn{2}{|l|}{ Comorbidities } \\
\hline Cardiovascular diseases, $n(\%)$ & $10(55.5)$ \\
\hline Renal diseases, $n(\%)$ & $5(27.7)$ \\
\hline Lung diseases, $n$ (\%) & $2(11.1)$ \\
\hline Diabetes (\%) & $4(22.2)$ \\
\hline Oncologic diseases (\%) & $2(11.1)$ \\
\hline Immunocompromised state (\%) & $1(5.5)$ \\
\hline \multicolumn{2}{|l|}{ Outcome } \\
\hline NIV failure, $n(\%)$ & $10(55.5)$ \\
\hline Time to intubation (h) & $12.5[9.5-24.2]$ \\
\hline Length of stay in emergency department (days) & $6[3.2-9]$ \\
\hline Hospital length of stay (days) & 17 [12-29] \\
\hline Emergency department mortality, $n$ (\%) & $6(33)$ \\
\hline In-hospital mortality, n (\%) & $8(44.4)$ \\
\hline
\end{tabular}

Values are displayed as means \pm SD or as medians [interquartile range] when appropriate. Normal distribution was assessed with the Kolmogorov-Smirnov test

$\mathrm{FiO}_{2}$ denotes fraction of inspired oxygen,

$\mathrm{PaCO}_{2}$ partial pressure of arterial carbon dioxide, and $\mathrm{PaO}_{2}$ partial pressure of arterial oxygen

${ }^{a}$ The body-mass index is the weight in kilograms divided by the square of the height in meters

${ }^{b}$ The Simplified Acute Physiology Score (SAPS) II was calculated from 17 variables at enrolment, information about previous health status and information obtained at admission. Scores range from 0 to 163 , with higher scores indicating more severe disease

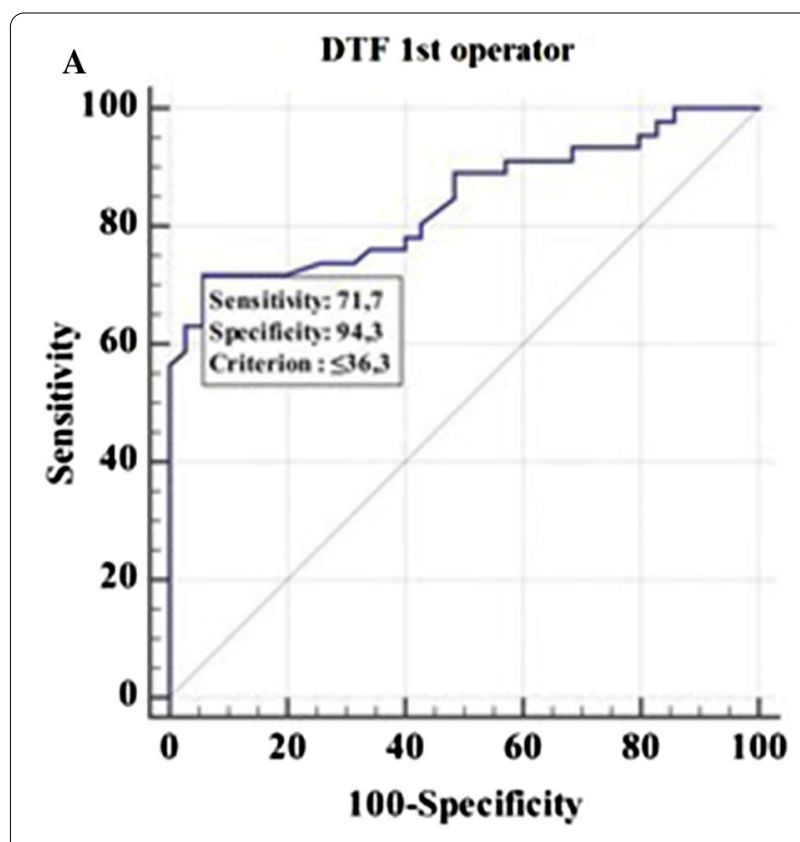

B

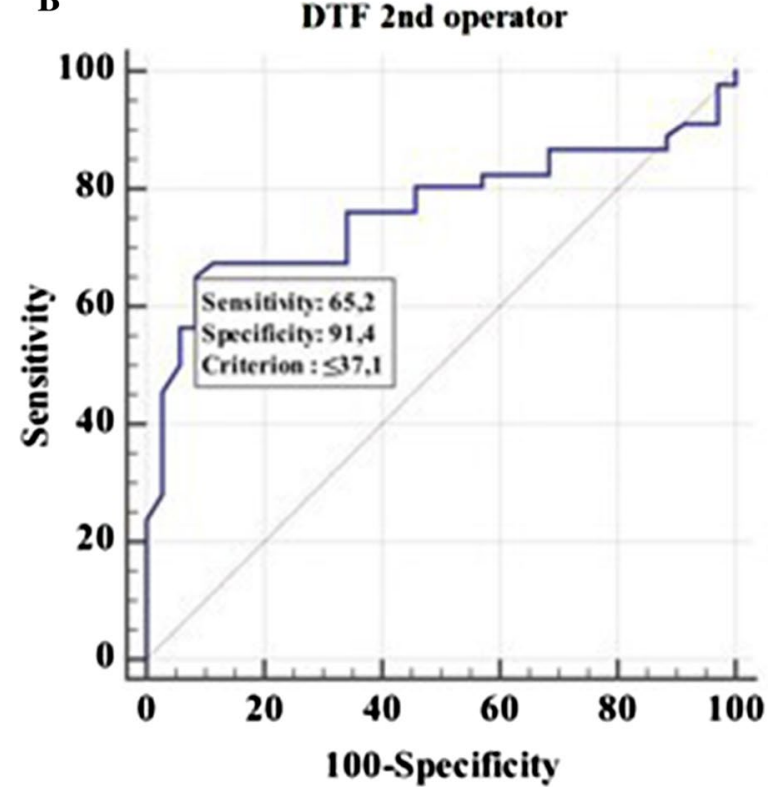

Fig. 2 Receiver operator characteristic curve (ROC) to assess the ability of the Diaphragm Thickening Fraction (DTF) to predict noninvasive ventilation (NIV) outcome for operator 1 (A) and 2 (B), respectively. Area under the ROC curve (AUC) 0.84 ( $95 \% \mathrm{Cl} 0.74$ to 0.91) for operator 1 and 0.76 (95\% Cl 0.65 to 0.85 ) for operator 2

The rate of NIV failure was 55.5\% (10 out of 18). Patients who required intubation among these were $80 \%$ (8 out of 10 ).

NIV success patients compared to NIV failure patients had significantly higher mean (SD) $\mathrm{PaO}_{2} / \mathrm{FiO}_{2}$ in the

\section{Clinical outcomes}

NIV median time [IQR] without discontinuation was 3 [2.2-32.2] hours for patients that did not need endotracheal intubation, and 12.5 [9.5-24.2] hours for the ones that required endotracheal intubation. 

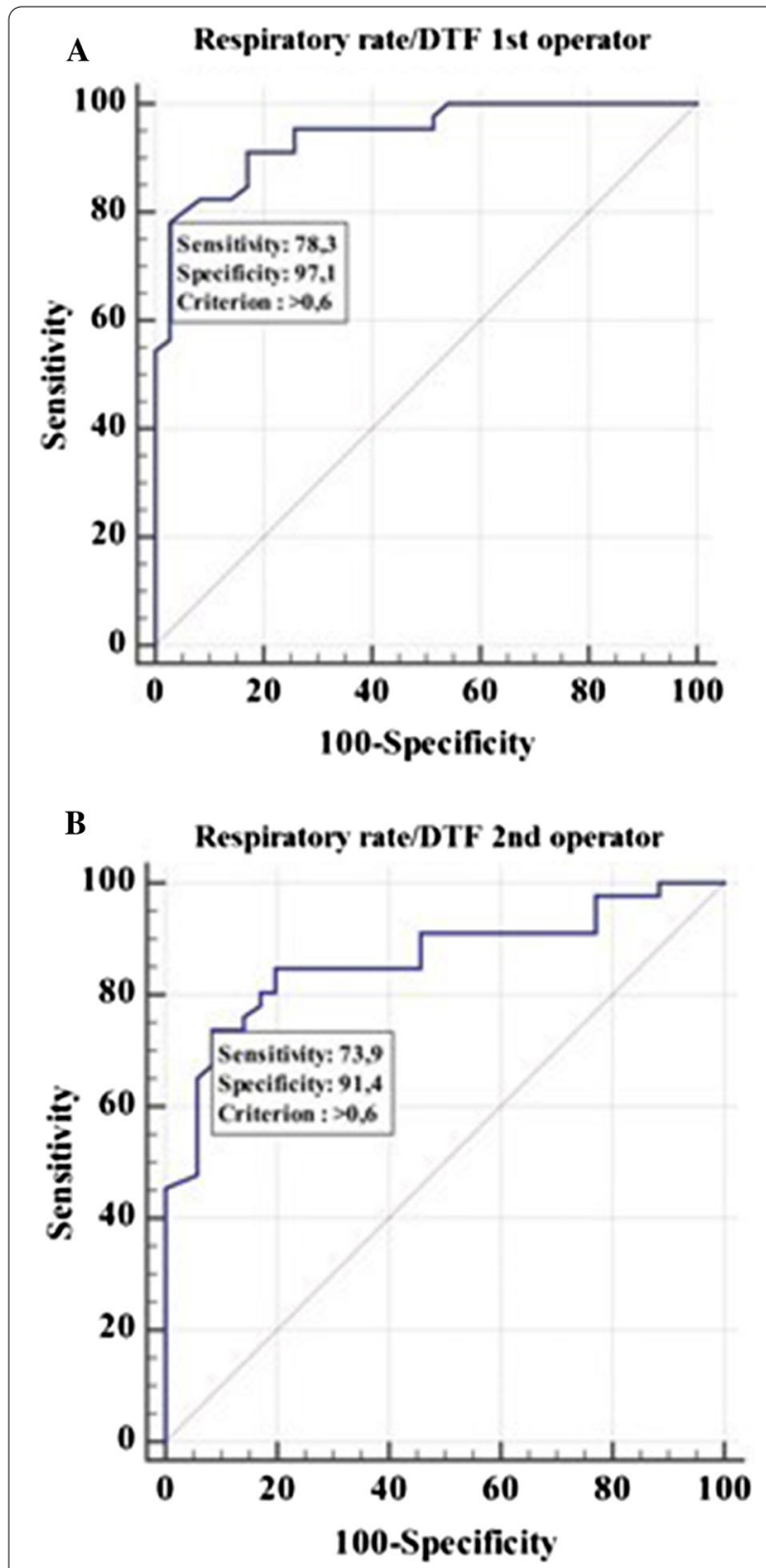

Fig. 3 Receiver operator characteristic curve (ROC) to assess the ability of the respiratory rate/DTF to predict noninvasive (NIV) outcome for operator 1 (A) and 2 (B), respectively. Area under the ROC curve (AUC) 0.94 (95\% Cl 0.86 to 0.98) for operator 1 and 0.86 ( $95 \% \mathrm{Cl} 0.77$ to 0.93 ) for operator 2

first $96 \mathrm{~h}$ [236 (118) vs 163 (67), $p<0.001]$, lower respiratory rate [24 (9) vs 30 (9) breaths per minute, $p<0.001$ ] and similar $\mathrm{PaCO}_{2}$ [35 (11) vs 35 (13) $\mathrm{mmHg}, p=0.99$ ] (Fig. 5A-C, Table 2).
During stay in the emergency department, ARDS was described in 6 patients (33\%), sepsis in 1 patient (5\%) and septic shock in 4 patients $(22 \%)$. The median [IQR] length of stay in the emergency department and in-hospital were 6 [3.2-9] and 17 [12-29] days, respectively.

The overall mortality in the emergency department was $33.3 \%$ and it was higher in intubated than in nonintubated patients $(75 \%$ vs $0 \%, p=0.023$ ).

The means $(95 \% \mathrm{CI})$ of DTF (\%) and the respiratory rate/DTF obtained by two operators between NIV success and NIV failure during the first $96 \mathrm{~h}$ are reported in Table 3.

\section{Discussion}

To our knowledge, this is the first study that evaluates DTF as a predictive index of NIV outcome in patients with de-novo ARF admitted to the emergency department.

Our study shows that DTF with a cut-off lower than $36.3 \%$ could predict NIV failure in hypoxemic patients, confirming previous results in other population $[18,26$, 27]. In a prospective observational study including 63 patients with ARF of various origin, Di Nino et al. [18] found that a cut-off value of DTF $\geq 30 \%$ predicted extubation success regardless of the used weaning technique.

In a cohort of chronic patients ventilated in PSV through a tracheostomy tube, Ferrari et al. [26] reported that a cut-off value of DTF $\geq 36 \%$ was associated with a successful weaning after spontaneous breathing trial.

In a recent systematic review, Zambon et al. [27] evaluated 20 studies including a total of 875 critically ill patients where ultrasound was performed to detect diaphragmatic dysfunction. The authors used both diaphragmatic excursion and DTF to predict extubation success or failure during weaning and reported that the optimal cut-offs ranged from 10 to $14 \mathrm{~mm}$ and $30-36 \%$, respectively.

Our study is the first to focus on hypoxemic patients during NIV treatment. However, the cut-off value of DTF that identified patients at major risk of NIV failure was similar to the cut-off value reported for critically ill patients requiring invasive mechanical ventilation [27], thus suggesting that DTF assessment is reliable to detect diaphragm dysfunction in hypoxemic patients on NIV treatment, as well.

In our study, we also assessed the reproducibility of DTF measurements. The ICC represents the proportion of total variance due to the variation between the subjects [27]. An ICC equal to 1 shows that the total variance is only due to the variation between the subjects, 


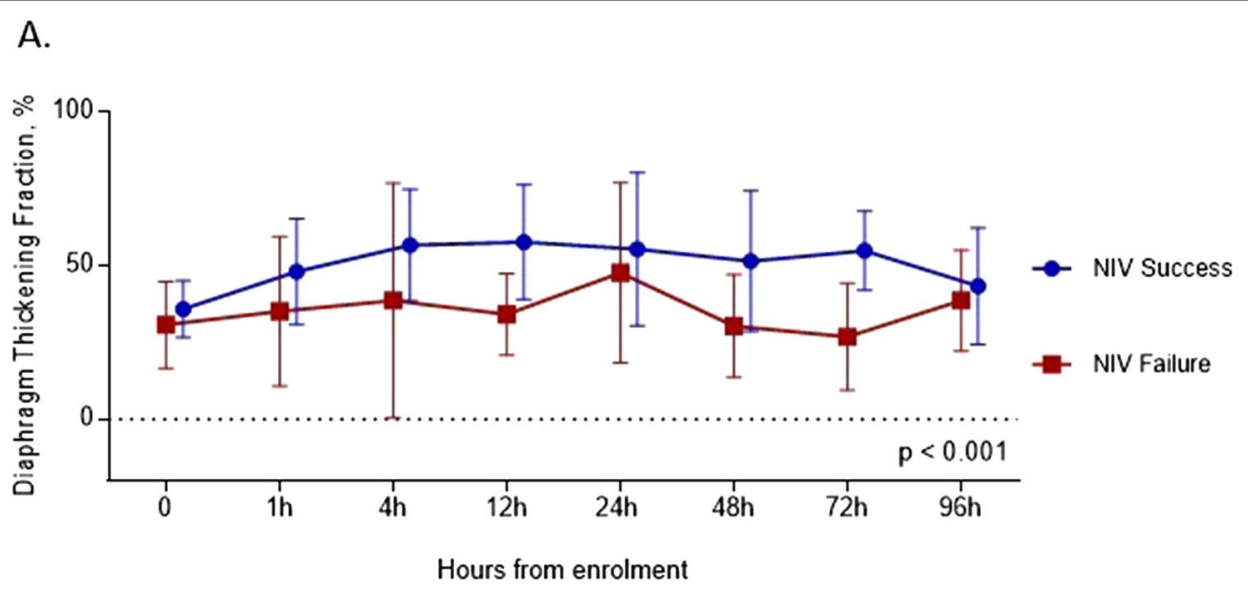

B.

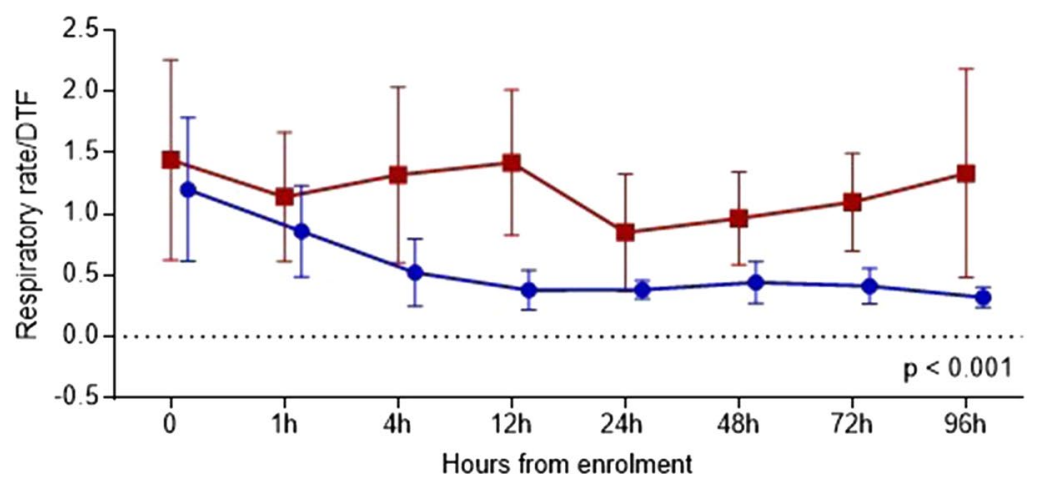

Fig. 4 DTF (A) and respiratory rate/DTF (B) in the NIV success and in the NIV failure group over time; the values displayed are the mean of the measures of the two operators. Patients were censored after endotracheal intubation. Comparisons between groups were performed with 1-way analysis of variance. Each point on the graph represents the mean values, and error bars represent Standard Deviation

while an ICC equal to 0 indicates that the total variance is attributed to the variation between observers. The two operators performing ultrasound assessments in our study were appropriately trained [24] and all measurements were obtained in blind. We found overall good repeatability of DTF measurements, with ICC above the 0.75 cut-off that is usually considered as an index of good agreement among operators [28, 29]. Given the expertise of our evaluators and the overall good repeatability of DTF assessment, we don't expect that further skilled operators could affect inter-rater agreement, as reported by other authors [15].

Considering that previous studies established a correlation between DTF and respiratory workload [15, 30-32], in a preliminary analysis we also explored the possibility that the respiratory rate/DTF ratio could be a valid predictive index of NIV failure.

In our study, the respiratory rate/DTF ratio intended to represent an ultrasound surrogate of rapid shallow breathing index [9], one of the most used and studied weaning predictors in the clinical practice [33]. We did not report the rapid shallow breathing index since it could be not accurate in patients who were spontaneously breathing. We therefore believe that another physiologic study should be performed to compare this index with the values measured by ultrasound.

We found that the cut-off value of respiratory rate/ DTF ratio $>0.6$ was a reliable predictor of NIV outcome in patients with de-novo ARF admitted to the emergency department.

Recently, several authors have reported the beneficial and detrimental effects of spontaneous breathing in acutely ill patients $[34,35]$. The entity of inspiratory effort that is surrogated in the clinical practice by the negative swing in the esophageal pressure $\left(P_{e s}\right)$ has been indicated as a possible aggravating mechanism of lung injury in patients with hypoxemic ARF [34,35]. On the other hand, the active movements of the diaphragm may 


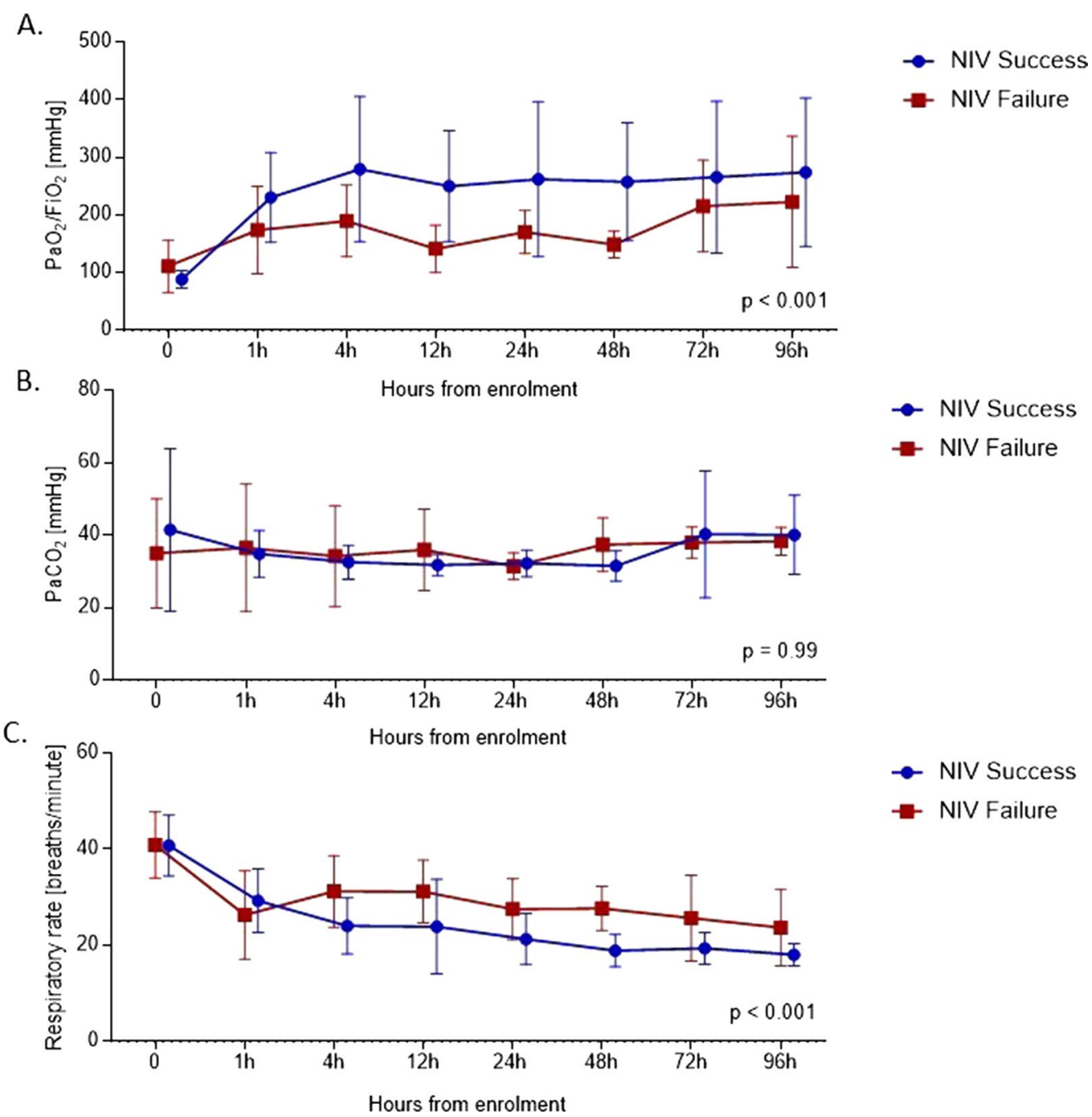

Fig. $5 \mathrm{PaO}_{2}(\mathbf{A}), \mathrm{PaCO}_{2}(\mathbf{B})$ and respiratory rate $(\mathbf{C})$ in the NIV success and in the NIV failure group over time. Patients were censored after endotracheal intubation. Comparisons between groups were performed with 1-way analysis of variance. Each point on the graph represents the mean values, and error bars represent Standard Deviation

permit to recruit the dependent lung zones and maintain the end-expiratory lung volume, while the cranial shifts of the diaphragm due to the use of excessive sedation and/or neuromuscular blockade drugs may cause a significant decrease in end-expiratory lung volume [36]. Evidence for beneficial effects of spontaneous breathing has been provided only for patients with normal lungs and less severe forms of ARDS who have mild ventilatory requests [37]. In these patients, spontaneous breathing and NIV may improve gas exchange by the recruiting effect of PEEP, the improvement of hemodynamics and the avoidance of diaphragm atrophy [37].
In a recent observational study conducted on 30 patients with hypoxemic ARF who were candidate for a 24-h NIV trial, Tonelli et al. [38] found that a change in $\Delta P_{e s}$ less than $10 \mathrm{cmH}_{2} 0$ within the first $2 \mathrm{~h}$ of NIV treatment was an accurate predictor of NIV outcome at $24 \mathrm{~h}$, when compared to other variables. The authors also reported that in patients with moderate to severe hypoxemic ARF, the reduction in the inspiratory effort clinically translate into a significant improvement of oxygenation and a decrease of both respiratory rate and tidal volume. 
Table 2 Physiological outcomes in the two groups in the first $96 \mathrm{~h}$

\begin{tabular}{|c|c|c|c|}
\hline \multirow[t]{2}{*}{ Outcome } & \multicolumn{2}{|l|}{ Study group } & \multirow[t]{2}{*}{$P$ value } \\
\hline & NIV success $(n=8)$ & NIV failure $(n=10)$ & \\
\hline \multicolumn{4}{|c|}{ Diaphragm thickening fraction in the first $96 \mathrm{~h}$ after enrolment (\%) } \\
\hline 1st operator & $54.6(47.3-61.9)$ & $31.8(26.1-37.6)$ & $<0.001$ \\
\hline 2nd operator & $48.1(42.9-53.3)$ & $37.3(29.8-44.8)$ & 0.016 \\
\hline Mean between the 2 operators & $52.1(45.7-58.5)$ & $34.3(28.6-40)$ & $<0.001$ \\
\hline \multicolumn{4}{|c|}{ Respiratory rate/Diaphragm thickening fraction in the first $96 \mathrm{~h}$ after enrolment } \\
\hline 1st operator & $0.55(0.45-0.66)$ & $1.4(1.1-1.6)$ & $<0.001$ \\
\hline 2nd operator & $0.61(0.49-0.73)$ & $1.1(0.89-1.28)$ & $<0.001$ \\
\hline Mean between the 2 operators & $0.58(0.47-0.69)$ & $1.24(1.05-1.42)$ & $<0.001$ \\
\hline \multicolumn{4}{|c|}{$\mathrm{PaO}_{2} / \mathrm{FiO}_{2}$ ratio in the first $96 \mathrm{~h}$ after enrolment $(\mathrm{mmHg})$} \\
\hline & $236(206-267)$ & $163(144-183)$ & $<0.001$ \\
\hline \multicolumn{4}{|c|}{$\mathrm{PaCO}_{2}$ in the first $96 \mathrm{~h}$ after enrolment $(\mathrm{mmHg})$} \\
\hline & $35(32-38)$ & $35(32-39)$ & 0.99 \\
\hline \multicolumn{4}{|c|}{ Respiratory rate in the first $96 \mathrm{~h}$ after enrolment, breaths per minute } \\
\hline & $24(22-27)$ & $31(28-33)$ & $<0.001$ \\
\hline
\end{tabular}

Results are displayed as Means $(95 \% \mathrm{Cl}) . P$ values are calculated with one-way ANOVA

NIV non-invasive ventilation

Other authors [39] have also reported that the progressive development of diaphragm atrophy as well as the rapid early increases in diaphragm thickening during ventilation are associated with prolonged mechanical ventilation and an increased risk of complications.

Our study has demonstrated that a value of respiratory rate/DTF ratio $>0.6$ is accurate to predict the NIV outcome in hypoxemic patients. However, we are far from understanding the mechanisms leading to worsening respiratory failure and intubation (excessive respiratory workload/inadequate unloading of the respiratory muscles versus diaphragm atrophy) since the inspiratory effort was not measured in our study population.

In hypoxemic ARF patients, NIV treatment improves respiratory discomfort [40] and reduces the need of intubation, the rate of infections and the intensive care unit mortality [41]. However, high rates of NIV failure ranging between 30 and 50\% [42] are related to an increased mortality [43], most likely due to the prolonged exposure of injured lungs to high swings in $P_{e s}$ and increased tidal volumes.

In our study, the percentage of patients who failed NIV treatment and required intubation in patients with de-novo ARF was similar to the percentage reported by other authors [42], thus confirming that unsuccessful NIV is related to poor outcomes [5, 43].

\section{Limitations}

Our study has some limitations.

First, this is a preliminary study with a small sample size that could have affected the width of sensitivity confidence interval for both operators.

Second, we did not measure inspiratory effort that is considered an early accurate predictor of NIV outcome [38].

Third, we could only evaluate the right hemi-diaphragm due to the presence of the liver as an appropriate ultrasound window that allowed us to obtain optimal images.

However, without diaphragm lesions or paralysis it is unlikely that the assessment of the left hemi-diaphragm might have changed the results of the present study.

\section{Conclusions}

Both DTF and respiratory rate/DTF ratio may represent valid, feasible and noninvasive tools to predict the NIV outcome in patients with de-novo ARF.

Ultrasound monitoring of diaphragmatic function should be encouraged as an integral part of clinical practice when defining the correct timing of NIV discontinuation and/or the need of intubation.

However, future studies should be conducted on a large group of patients to address the ability of DTF and respiratory rate/DTF ratio to predict the NIV outcome. 
Table 3 Physiological outcomes in the two groups at different study time points

\begin{tabular}{|c|c|c|c|}
\hline \multirow[t]{2}{*}{ Outcome } & \multicolumn{2}{|l|}{ Study group } & \multirow[t]{2}{*}{$P$ value } \\
\hline & NIV success $(n=8)$ & NIV failure $(n=10)$ & \\
\hline \multicolumn{4}{|c|}{ Diaphragm thickening fraction (\%) } \\
\hline At the enrolment & $35[25.8-67.4]$ & $41.5[22-56]$ & 0.864 \\
\hline $1 \mathrm{~h}$ after the enrolment & $37.9[25.2-50.9]$ & $30.1[17.8-43.6]$ & 0.41 \\
\hline $4 \mathrm{~h}$ after the enrolment & $54.2[41-72.6]$ & $28.2[19.2-53.8]$ & 0.114 \\
\hline $12 \mathrm{~h}$ after the enrolment & $53[39.3-74]$ & $27.4[21.9-34.5]$ & 0.032 \\
\hline $24 \mathrm{~h}$ after the enrolment & $55.1[38-80.9]$ & $33.3[26.9-63.9]$ & 0.114 \\
\hline $48 \mathrm{~h}$ after the enrolment & $43.3[39-54.4]$ & $32.5[23.8-32.5]$ & 0.067 \\
\hline $72 \mathrm{~h}$ after the enrolment & $47.5[39-56]$ & $19.7[15.1-19.7]$ & 0.383 \\
\hline $96 \mathrm{~h}$ after the enrolment & $56.9[45.7-80.3]$ & $23.3[15.8-23.3]$ & 0.071 \\
\hline \multicolumn{4}{|c|}{ Respiratory rate/Diaphragm thickening fraction } \\
\hline At the enrolment & $1.19[0.84-1.55]$ & $1.09[0.73-2.42]$ & 0.776 \\
\hline $1 \mathrm{~h}$ after the enrolment & $0.69[0.64-1.24]$ & $1.16[0.61-1.61]$ & 0.315 \\
\hline $4 \mathrm{~h}$ after the enrolment & $0.40[0.32-0.78]$ & $1.21[0.66-1.99]$ & 0.008 \\
\hline $12 \mathrm{~h}$ after the enrolment & $0.33[0.27-0.55]$ & $1.39[0.83-2.00]$ & 0.008 \\
\hline $24 \mathrm{~h}$ after the enrolment & $0.40[0.29-0.43]$ & $0.75[0.42-1.32]$ & 0.114 \\
\hline $48 \mathrm{~h}$ after the enrolment & $0.42[0.31-0.60]$ & $0.78[0.69-0.78]$ & 0.033 \\
\hline $72 \mathrm{~h}$ after the enrolment & $0.34[0.32-0.58]$ & $1.07[0.65-1.07]$ & 0.017 \\
\hline $96 \mathrm{~h}$ after the enrolment & $0.34[0.23-0.37]$ & $0.99[0.71-0.99]$ & 0.036 \\
\hline \multicolumn{4}{|l|}{$\mathrm{PaO}_{2} / \mathrm{FiO}_{2}$ ratio $(\mathrm{mmHg})$} \\
\hline At the enrolment & 87 [75-92] & 103 [76-148] & 0.36 \\
\hline $1 \mathrm{~h}$ after the enrolment & $197[164-301]$ & $140[112-221]$ & 0.083 \\
\hline $4 \mathrm{~h}$ after the enrolment & 256 [165-423] & 189 [132-246] & 0.20 \\
\hline $12 \mathrm{~h}$ after the enrolment & 245 [152-309] & 133 [115-177] & 0.022 \\
\hline $24 \mathrm{~h}$ after the enrolment & 214 [184-406] & 173 [134-204] & 0.154 \\
\hline $48 \mathrm{~h}$ after the enrolment & 256 [197-282] & $158[121-158]$ & 0.117 \\
\hline $72 \mathrm{~h}$ after the enrolment & 246 [199-382] & $172[165-172]$ & 0.517 \\
\hline $96 \mathrm{~h}$ after the enrolment & $261[225-395]$ & 162 [152-162] & 0.517 \\
\hline \multicolumn{4}{|l|}{$\mathrm{PaCO}_{2}(\mathrm{mmHg})$} \\
\hline At the enrolment & 31 [29-49] & 30 [25-39] & 0.515 \\
\hline $1 \mathrm{~h}$ after the enrolment & $34[30-41]$ & $32[24-42]$ & 0.696 \\
\hline $4 \mathrm{~h}$ after the enrolment & $32[30-37]$ & $30[25-44]$ & 0.673 \\
\hline $12 \mathrm{~h}$ after the enrolment & $31[30-34]$ & $34[28-44]$ & 0.445 \\
\hline $24 \mathrm{~h}$ after the enrolment & $32[28-36]$ & 31 [28-35] & 0.683 \\
\hline $48 \mathrm{~h}$ after the enrolment & 32 [29-35] & $34[32-34]$ & 0.383 \\
\hline $72 \mathrm{~h}$ after the enrolment & $32[30-45]$ & $40[33-40]$ & 0.517 \\
\hline $96 \mathrm{~h}$ after the enrolment & $44[28-48]$ & 37 [35-37] & 0.883 \\
\hline \multicolumn{4}{|c|}{ Respiratory rate, breaths per minute } \\
\hline At the enrolment & $38[36-48]$ & $38[36-46]$ & 0.96 \\
\hline $1 \mathrm{~h}$ after the enrolment & $29[23-36]$ & $26[19-34]$ & 0.51 \\
\hline $4 \mathrm{~h}$ after the enrolment & 22 [19-28] & $30[25-38]$ & 0.036 \\
\hline $12 \mathrm{~h}$ after the enrolment & $22[16-25]$ & $29[27-34]$ & 0.020 \\
\hline $24 \mathrm{~h}$ after the enrolment & $21[16-26]$ & $26[22-34]$ & 0.154 \\
\hline $48 \mathrm{~h}$ after the enrolment & 18 [15-22] & 25 [25-25] & 0.012 \\
\hline $72 \mathrm{~h}$ after the enrolment & 18 [18-21] & $21[20,21]$ & 0.133 \\
\hline $96 \mathrm{~h}$ after the enrolment & $18[15-20]$ & $23[16-23]$ & 0.279 \\
\hline
\end{tabular}

Results are displayed as Medians [Interquartile Range]. $P$ values are calculated with Mann-U-Whitney test NIV non-invasive ventilation 


\begin{abstract}
Abbreviations
ARDS: Acute respiratory distress syndrome; ARF: Acute respiratory failure: ANOVA: Analysis of variance; BMI: Body Mass Index; DT: Diaphragmatic thickness; DTF: Diaphragmatic thickening fraction; Pes: Esophageal pressure; ICC: Intra-class correlation coefficient; NIV: Non-Invasive ventilation; SpO2: Peripheral oxygen saturation; PEEP: Positive end-expiratory pressure; PSV: Pressure support ventilation; PTPdi: Pressure-time product per breath; ROC: Receiver operating characteristic; RASS: Richmond Agitation-Sedation Scale; SAPS II: Simplified Acute Physiologic Score.
\end{abstract}

\section{Acknowledgements}

The authors are grateful to all intensive care unit doctors, residents, nurses and personnel, whose sacrifice, efforts, devotion to patients and passion have made possible this timely report.

\section{Authors' contributions}

GM, LM and SD designed the study. GM, SD, DLG, LSM, AR, DE, MGA, MGB, GB conducted the study on enrolled patients. RM analyzed the data. GM and SD interpreted the data and wrote the manuscript. GC, MAP and MA revised the manuscript for important intellectual content. All the authors reviewed the final draft of the manuscript and MA approved the final version to be published on Critical Care. All authors read and approved the final manuscript.

\section{Funding}

Not applicable.

\section{Availability of data and materials}

The datasets used and/or analysed during the current study are available from the corresponding author on reasonable request.

\section{Declarations}

\section{Ethics approval and consent to participate}

The protocol was approved by the local Ethics Committee (Prot 20813/16 ID 1200) and informed consent was obtained by all study participants.

\section{Consent for publication}

Not applicable.

\section{Competing interests}

MA has received payments for Board participation from Maquet, Air Liquide and Chiesi. GC has received payments for lectures from Chiesi Pharmaceuticals SpA. DLG has received payments for travel expenses by Maquet, Getinge and Air Liquide. DLG and MA disclose a research grant by General Electric Healthcare.

\section{Author details}

${ }^{1}$ Department of Anesthesiology, Intensive Care and Emergency Medicine, Fondazione Policlinico Universitario A. Gemelli IRCCS, Largo A. Gemelli, 8, 00168 Rome, Italy. ${ }^{2}$ Biostatistics, Office of the Scientific Director, Fondazione Policlinico Universitario A. Gemelli IRCCS, Rome, Italy. ${ }^{3}$ Institute of Anesthesiology and Intensive Care Medicine, Catholic University of the Sacred Heart, Rome, Italy.

Received: 13 April 2021 Accepted: 9 June 2021

Published online: 26 June 2021

\section{References}

1. Antonelli M, Conti G, Rocco M, Bufi M, De Blasi RA, Vivino G, et al. A comparison of noninvasive positive-pressure ventilation and conventional mechanical ventilation in patients with acute respiratory failure. N Engl J Med. 1998:339(7):429-35.

2. Hilbert G, Gruson D, Vargas F, Valentino R, Gbikpi-Benissan G, Dupon $M$, et al. Noninvasive ventilation in immunosuppressed patients with pulmonary infiltrates, fever, and acute respiratory failure. N Engl J Med. 2001:344(7):481-7.

3. Cabrini L, Landoni G, Oriani A, Plumari VP, Nobile L, Greco M, et al. Noninvasive ventilation and survival in acute care settings: a comprehensive systematic review and metaanalysis of randomized controlled trials. Crit Care Med. 2015;43(4):880-8.

4. Ferreyro BL, Angriman F, Munshi L, Del Sorbo L, Ferguson ND, Rochwerg $B$, et al. Association of noninvasive oxygenation strategies with all-cause mortality in adults with acute hypoxemic respiratory failure: a systematic review and meta-analysis. JAMA. 2020;324(1):57-67.

5. Demoule A, Girou E, Richard JC, Taille S. Brochard L Benefits and risks of success or failure of noninvasive ventilation. Intensive Care Med. 2006:32(11):1756-65.

6. Antonelli M, Conti G, Moro ML, Esquinas A, Gonzalez-Diaz G, Confalonieri $M$, et al. Predictors of failure of noninvasive positive pressure ventilation in patients with acute hypoxemic respiratory failure: a multi-center study. Intensive Care Med. 2001;27(11):1718-28.

7. Milic-Emili J. Is weaning an art or a science? Am Rev Respir Dis. 1986;134(6):1107-8

8. Laghi F. Fernandez R Noninvasive ventilation for weaning in hypoxemic respiratory failure: not ready for prime time. Intensive Care Med. 2012;38(10):1583-5.

9. Yang KL, Tobin MJ. A prospective study of indexes predicting the outcome of trials of weaning from mechanical ventilation. N Engl J Med. 1991;324(21):1445-50.

10. Vassilakopoulos T, Zakynthinos S. Roussos C The tension-time index and the frequency/tidal volume ratio are the major pathophysiologic determinants of weaning failure and success. Am J Respir Crit Care Med. 1998;158(2):378-85.

11. Petrof BJ, Jaber S, Matecki S. Ventilator-induced diaphragmatic dysfunction. Curr Opin Crit Care. 2010;16(1):19-25.

12. Annetta MG, Pittiruti M, Silvestri D, Grieco DL, Maccaglia A, La Torre MF, et al. Ultrasound assessment of rectus femoris and anterior tibialis muscles in young trauma patients. Ann Intensive Care. 2017;7(1):104.

13. Matamis D, Soilemezi E, Tsagourias M, Akoumianaki E, Dimassi S, Boroli F, et al. Sonographic evaluation of the diaphragm in critically ill patients. Technique and clinical applications. Intensive Care Med. 2013;39(5):801-10

14. Lerolle N, Guérot E, Dimassi S, Zegdi R, Faisy C, Fagon JY, et al. Ultrasonographic diagnostic criterion for severe diaphragmatic dysfunction after cardiac surgery. Chest. 2009;135(2):401-7.

15. Vivier E, Mekontso Dessap A, Dimassi S, Vargas F, Lyazidi A, Thille AW, et al Diaphragm ultrasonography to estimate the work of breathing during non-invasive ventilation. Intensive Care Med. 2012;38(5):796-803.

16. Cohn D, Benditt JO, Eveloff S. McCool FD Diaphragm thickening during inspiration. J Appl Physiol (1985). 1997:83(1):291-6.

17. McCool FD, Conomos P, Benditt JO, Cohn D, Sherman CB, Hoppin FG Jr. Maximal inspiratory pressures and dimensions of the diaphragm. Am J Respir Crit Care Med. 1997;155(4):1329-34.

18. DiNino E, Gartman EJ, Sethi JM. McCool FD Diaphragm ultrasound as a predictor of successful extubation from mechanical ventilation. Thorax. 2014;69(5):423-7.

19. Brower RG, Matthay MA, Morris A, Schoenfeld D, Thompson BT, Wheeler A. Ventilation with lower tidal volumes as compared with traditional tidal volumes for acute lung injury and the acute respiratory distress syndrome. N Engl J Med. 2000;342(18):1301-8.

20. Le Gall JR, Lemeshow S, Saulnier F. A new Simplified Acute Physiology Score (SAPS II) based on a European/North American multicenter study. JAMA. 1993:270(24):2957-63.

21. Ely EW, Truman B, Shintani A, Thomason JW, Wheeler AP, Gordon S, et al. Monitoring sedation status over time in ICU patients: reliability and validity of the Richmond Agitation-Sedation Scale (RASS). JAMA. 2003;289(22):2983-91.

22. Singer M, Deutschman CS, Seymour CW, Shankar-Hari M, Annane D, Bauer $M$, et al. The third international consensus definitions for sepsis and septic shock (Sepsis-3). JAMA. 2016;315(8):801-10.

23. Ranieri VM, Rubenfeld GD, Thompson BT, Ferguson ND, Caldwell E, Fan $\mathrm{E}$, et al. Acute respiratory distress syndrome: the Berlin Definition. JAMA 2012;307(23):2526-33.

24. Garofalo E, Bruni A, Pelaia C, Landoni G, Zangrillo A, Antonelli M, et al. Comparisons of two diaphragm ultrasound-teaching programs: a multicenter randomized controlled educational study. Ultrasound J. 2019;11(1):21.

25. Bland JM, Altman DG. Measurement error and correlation coefficients. BMJ. 1996:313(7048):41-2. 
26. Ferrari G, De Filippi G, Elia F, Panero F, Volpicelli G, Aprà F. Diaphragm ultrasound as a new index of discontinuation from mechanical ventilation. Crit Ultrasound J. 2014;6(1):8.

27. Zambon M, Greco M, Bocchino S, Cabrini L, Beccaria PF, Zangrillo A. Assessment of diaphragmatic dysfunction in the critically ill patient with ultrasound: a systematic review. Intensive Care Med. 2017;43(1):29-38.

28. Kramer MS, Feinstein AR. Clinical biostatistics. LIV. The biostatistics of concordance. Clin Pharmacol Ther. 1981;29(1):111-23.

29. Wait JL, Nahormek PA, Yost WT, Rochester DP. Diaphragmatic thicknesslung volume relationship in vivo. J Appl Physiol (1985). 1989;67(4):1560-8.

30. Goligher EC, Laghi F, Detsky ME, Farias P, Murray A, Brace D, et al. Measuring diaphragm thickness with ultrasound in mechanically ventilated patients: feasibility, reproducibility and validity. Intensive Care Med. 2015:41(4):642-9.

31. Spadaro S, Grasso S, Mauri T, Dalla Corte F, Alvisi V, Ragazzi R, et al. Can diaphragmatic ultrasonography performed during the T-tube trial predict weaning failure? The role of diaphragmatic rapid shallow breathing index. Crit Care. 2016;20(1):305.

32. Marchioni A, Castaniere I, Tonelli R, Fantini R, Fontana M, Tabbì L, et al. Ultrasound-assessed diaphragmatic impairment is a predictor of outcomes in patients with acute exacerbation of chronic obstructive pulmonary disease undergoing noninvasive ventilation. Crit Care. 2018;22(1):109.

33. Berg KM, Lang GR, Salciccioli JD, Bak E, Cocchi MN, Gautam S, et al. The rapid shallow breathing index as a predictor of failure of noninvasive ventilation for patients with acute respiratory failure. Respir Care. 2012;57(10):1548-54.

34. Yoshida T, Amato MBP, Kavanagh BP, Fujino Y. Impact of spontaneous breathing during mechanical ventilation in acute respiratory distress syndrome. Curr Opin Crit Care. 2019;25(2):192-8.

35. Yoshida T, Roldan R, Beraldo MA, Torsani V, Gomes S, De Santis RR, et al. Spontaneous effort during mechanical ventilation: maximal injury with less positive end-expiratory pressure. Crit Care Med. 2016;44(8):e678-88.
36. Hedenstierna G, Edmark L. The effects of anesthesia and muscle paralysis on the respiratory system. Intensive Care Med. 2005;31(10):1327-35.

37. Putensen C, Zech S, Wrigge H, Zinserling J, Stüber F, Von Spiegel T, et al. Long-term effects of spontaneous breathing during ventilatory support in patients with acute lung injury. Am J Respir Crit Care Med. 2001;164(1):43-9.

38. Tonelli R, Fantini R, Tabbì L, Castaniere I, Pisani L, Pellegrino MR, et al. Early inspiratory effort assessment by esophageal manometry predicts noninvasive ventilation outcome in de novo respiratory failure. A Pilot Study. Am J Respir Crit Care Med. 2020;202(4):558-67.

39. Goligher EC, Dres M, Fan E, Rubenfeld GD, Scales DC, Herridge MS, et al. Mechanical ventilation-induced diaphragm atrophy strongly impacts clinical outcomes. Am J Respir Crit Care Med. 2018;197(2):204-13.

40. L'Her E, Deye N, Lellouche F, Taille S, Demoule A, Fraticelli A, et al. Physiologic effects of noninvasive ventilation during acute lung injury. Am J Respir Crit Care Med. 2005;172(9):1112-8.

41. Ferrer M, Esquinas A, Leon M, Gonzalez G, Alarcon A, Torres A. Noninvasive ventilation in severe hypoxemic respiratory failure: a randomized clinical trial. Am J Respir Crit Care Med. 2003;168(12):1438-44.

42. Demoule A, Chevret S, Carlucci A, Kouatchet A, Jaber S, Meziani F, et al. Changing use of noninvasive ventilation in critically ill patients: trends over 15 years in francophone countries. Intensive Care Med. 2016;42(1):82-92.

43. Esteban A, Anzueto A, Frutos F, Alía I, Brochard L, Stewart TE, et al. Characteristics and outcomes in adult patients receiving mechanical ventilation: a 28-day international study. JAMA. 2002;287(3):345-55.

\section{Publisher's Note}

Springer Nature remains neutral with regard to jurisdictional claims in published maps and institutional affiliations.
Ready to submit your research? Choose BMC and benefit from:

- fast, convenient online submission

- thorough peer review by experienced researchers in your field

- rapid publication on acceptance

- support for research data, including large and complex data types

- gold Open Access which fosters wider collaboration and increased citations

- maximum visibility for your research: over $100 \mathrm{M}$ website views per year

At BMC, research is always in progress.

Learn more biomedcentral.com/submissions 